\title{
Clinical outcomes of neonates with persistent pulmonary hypertension in a teaching hospital, Eastern India
}

\author{
Santosh Kumar Panda ${ }^{1}$, Nirmal Kumar Mohakud ${ }^{1}$, Soumini Rath ${ }^{1}$, Subhra Snigdha Panda ${ }^{2}$, Manas \\ Kumar Nayak ${ }^{1}$
}

Sri Lanka Journal of Child Health, 2021; 50(2): 272-279

\begin{abstract}
Background: Persistent pulmonary hypertension of the newborn (PPHN) is characterized by severe arterial hypoxaemia caused by increased pulmonary vascular resistance with resultant shunting through fetal channel (at the atrial and ductal level). Mortality of neonates due to PPHN ranges from 10$20 \%$.
\end{abstract}

Objectives: To describe the clinical outcomes of neonates presenting with PPHN in a tertiary care hospital.

Method: It is a hospital based prospective observational study, conducted from June 2016 to December 2018. All late preterm and term babies having respiratory distress and profound hypoxia were included in the study after confirmation of pulmonary hypertension by echocardiography.

Results: Our study highlighted hyaline membrane disease (HMD) as the most common cause of PPHN in preterm neonates whereas meconium aspiration syndrome (MAS) was mostly found in term neonates. Survival rate of PPHN with MAS, HMD, congenital diaphragmatic hernia, pulmonary hypoplasia and idiopathic PPHN was $77 \%, 72 \%$, $50 \%, 50 \%$ and $100 \%$ respectively. Left ventricular dysfunction was found in $28 \%$ babies who had died. Mean admission $\mathrm{pH}$ among survivors was 7.29 (7.25-7.32) and mean admission $\mathrm{pH}$ among nonsurvivors was 7.19 (7.11-7.26). Mean maximum oxygenation index (OI) among survivors was 19.4 (19.6-24.23) whereas the same in non survivors was

${ }^{1}$ Associate Professor, Department of Paediatrics,
KIMS, KIIT Deemed to be University, Odisha, India,
${ }^{2}$ Associate Professor, Department of Microbiology,
KIMS, KIIT Deemed to be University, Odisha, India
*Correspondence: drmanas_76@yahoo.co.in

iD https://orcid.org/0000-0001-8486-3417 (Keceived on 20 May 2020: Accepted after revision on 24 June 2020)

The authors declare that there are no conflicts of interest

Personal funding was used for the project.

Open Access Article published under the Creative

Commons Attribution CC-BY (c) (i) License
42.4 (23.8-60). Mortality rate increased to $66 \%$ if the OI was $>40$.

Conclusions: PPHN is a serious and often fatal condition, associated with a high mortality $(30 \%)$. Admission $\mathrm{pH}$, maximum oxygenation index, Apgar score $<5$ at 5 minutes, presence of left ventricular dysfunction and requirement of multiple inotropes were found to be significant predictors of higher mortality.

DOI: http://dx.doi.org/10.4038/sljch.v50i2.9570

(Key words: mortality, neonates, persistent pulmonary hypertension, hypoxia, HMD)

\section{Introduction}

Neonatal hypoxic respiratory failure affects $2 \%$ of all live births and is responsible for more than one third of all neonatal deaths ${ }^{1}$. Incidence is 1.8 to 2 per 1000 live births $s^{2,3}$ and it is likely to be higher in developing countries ${ }^{4,5}$. It affects $2 \%$ of preterm neonates who develop hyaline membrane disease $(\mathrm{HMD})^{6}$. Mortality rate ranges from $10-20 \%{ }^{7-10}$. Persistent pulmonary hypertension of the newborn (PPHN) is a clinical syndrome during the early neonatal period characterized by severe arterial hypoxaemia caused by increased pulmonary vascular resistance with resultant shunting through fetal channel (at the atrial and ductal level). The newborn with PPHN is typically a term or latepreterm infant who presents within hours of birth with severe hypoxic respiratory failure requiring assisted ventilation. $10 \%$ to $20 \%$ of affected infants still die even with advanced treatment modalities like nitric oxide (NO) and extracorporeal membrane oxygenation (ECMO $)^{7,9,10}$. Infants who survive PPHN also have increased risks for serious and longterm sequelae i.e. chronic lung disease, seizures, hearing defects and neurodevelopmental problems ${ }^{11}$. This study mainly focused on the clinical management and outcome of neonatal pulmonary hypertension in a tertiary care centre, where ECMO and NO therapy was not available.

\section{Objectives}

To describe the clinical outcomes of neonates presenting with PPHN in a tertiary care hospital. 


\section{Method}

This prospective observational study was done in the Kalinga Institute of Medical Sciences, Odisha, India from June 2016 to December 2018. A total of 1854 neonates was admitted in the neonatal intensive care unit (NICU) during the study period out of which eighty four $(4.5 \%)$ babies were diagnosed to have PPHN and were enrolled in the study.

Inclusion criteria: All late preterm and term neonates admitted in our NICU with respiratory distress and profound hypoxia were included in the study after confirmation of diagnosis. PPHN was diagnosed when a neonate having a structurally normal heart showed any of the following features:

- Severe hypoxaemia, usually a $\mathrm{PaO} 2$ less than $45 \mathrm{~mm} \mathrm{Hg}$ in a Fio2 of 1.0 and intermittent positive pressure ventilation, if necessary.

- Evidence of right to left or bidirectional haemodynamic shunting at ductus arteriosus (Usually $\mathrm{PaO}_{2}$ in post-ductal blood 7.5-15 $\mathrm{mm} \mathrm{Hg}$ lower than simultaneous pre-ductal $\mathrm{PaO}_{2}$ ) or at patent foramen ovale

- Pulmonary arterial systolic pressure (PASP) $>40 \mathrm{~mm} \mathrm{Hg}$

Exclusion criteria: Neonates with structural congenital heart disease (CHD) and multiple congenital anomalies were excluded from the study. Sample size: Considering PPHN mortality 31\% in previous study by Roofthooft et al and allowable error in $\mathrm{p} 10 \%$, the calculated sample size was $890^{11}$. Considering allowable error in p 50\%, the calculated sample size will be 35 . The sample size is calculated as per formula $=4 \mathrm{pq} / \mathrm{L} 2 \mathrm{p}=$ positive character, $q=1-p, L=$ allowable error in $p$

Considering our study is an exploratory study, we will prospectively recruit the cases during the study period. In our study sample size was 84 .
In these babies we had accessed associated conditions like sepsis, pneumonia, left ventricular dysfunction (LVD), use of multiple inotropes, Apgar score, $\mathrm{pH}$ at the time of admission, underdevelopment and maldevelopment lung pathophysiology and their correlation with mortality due to PPHN.

Ethical issues: Ethical approval was obtained from the Research Committee of Kalinga Institute of Medical Sciences, Bhubaneswar (No. KIMS/ KIIT/ IEC/097/2015), prior to the study. Written informed consent was obtained from the parents of the neonates participating in study.

Statistical analysis: Comparisons between categorical variables were done by Chi square test or Fisher exact test. Comparisons between continuous variables were done by Mann Whitney Test. Descriptive analysis was used to report demographic characteristics of the participants. These data were entered into Excel 2003 (Microsoft) and were analysed to evaluate the overall proportion. The level of significance was set at $p<0.05$. Statistical analysis was conducted using SPSS software version 21, SPSS Inc., Chicago, Illinois, USA.

\section{Results}

In our study, hyaline membrane disease (HMD) was the most common cause of PPHN in preterm babies and meconium aspiration syndrome (MAS) was more common among term babies. Surfactant was significantly more used in preterm neonates with PPHN which can be explained by more prevalence of HMD in preterms. There was no significant difference in incidence of moderate-severe disease, requirement of high frequency oscillation (HFO), mortality between preterm and term babies (Table 1). Out of 84 neonates diagnosed to have PPHN, 59 (70\%) babies survived and 25 (30\%) neonates died secondary to PPHN and its complication in our study.

Table 1: Comparison between preterm and term babies $(n=84)$

\begin{tabular}{|l|c|c|c|}
\hline & Preterm & Term & p value \\
\hline No. of patients & 18 & 66 & $<0.0001$ \\
\hline Birth weight $(\mathrm{kg})$ & $1.9(1.67-3.09)$ & $2.9(2.81-3.09)$ & 0.0025 \\
\hline Surfactant & 16 & 32 & 0.0002 \\
\hline Hyaline membrane disease & 13 & 13 & 0.032 \\
\hline Meconium aspiration syndrome & 01 & 21 & 0.78 \\
\hline High frequency oscillation & 11 & 36 & 0.508 \\
\hline Moderate pulmonary hypertension & 02 & 15 & 0.78 \\
\hline Severe pulmonary hypertension & 07 & 23 & 0.38 \\
\hline Mortality & 07 & 18 & \\
\hline
\end{tabular}

The survival rate in PPHN due to MAS and HMD were $77 \%$ (17) and 72\% (18) respectively (Table 2). Out of 14 neonates having congenital diaphragmatic hernia (CDH) with PPHN, 7 (50\%) neonates survived. Mean duration of surgical intervention was 4 days after stabilization of pulmonary hypertension. All neonates with idiopathic PPHN survived. Relative risk of death was higher in congenital diaphragmatic hernia $(\mathrm{CDH})(\mathrm{RR}=1.94$, $95 \%$ CI 1.007-3.54) followed by pulmonary hypoplasia group $(\mathrm{RR}=1.77,95 \% \mathrm{CI}$ 0.73-4.2). 
Table 2: Cause of pulmonary hypertension and outcome

\begin{tabular}{|l|c|c|c|c|}
\hline & Number & Survival (\%) & Death & Relative Risk \\
\hline Meconium aspiration syndrome & 22 & $17(77)$ & 05 & $0.704(0.30-1.6)$ \\
\hline Hyaline membrane disease & 25 & $18(72)$ & 97 & $0.910(0.43-1.9)$ \\
\hline Congenital diaphragmatic hernia & 14 & $07(50)$ & 07 & $1.941(007-3.54)$ \\
\hline Primary pulmonary hypertension & 08 & $08(100)$ & 0 & 0.00 \\
\hline Pneumonia & 09 & $06(66)$ & 03 & $1.130(42-3.04)$ \\
\hline Pulmonary hypoplasia & 06 & $03(50)$ & 03 & $1.77(0.73-4.2)$ \\
\hline
\end{tabular}

Forty nine $(75 \%)$ neonates survived who had a $\mathrm{pH}$ of $>7.20$ at the time of admission, but only $2(40 \%)$ neonates survived with admission $\mathrm{pH}$ of $<7$. Admission $\mathrm{pH}$ is statistically significant predictor of mortality $(\mathrm{p}=0.0061)$ (Table 3$)$.
The neonates with oxygenation index $(\mathrm{OI})>25-40$ had mortality risk of $43 \%$ and mortality risk was increased to $66 \%$ if OI was more than 40 (Table 4 ).

Table 3: Outcome based on arterial pH at the time of admission

\begin{tabular}{|l|c|c|}
\hline \multicolumn{1}{|c|}{$\mathbf{p H}$} & Number of patients & Survival \\
\hline$<7.00$ & 05 & $02(40 \%)$ \\
\hline $7.00-7.200$ & 14 & $07(50 \%)$ \\
\hline$>7.2 .00$ & 65 & $49(75 \%)$ \\
\hline
\end{tabular}

Table 4: Outcome based on maximum oxygenation index (OI)

\begin{tabular}{|l|c|c|}
\hline \multicolumn{1}{|c|}{ Oxygenation index (OI) } & No of patients (n) & Mortality (\%) \\
\hline$<15$ & 34 & $06(17 \%)$ \\
\hline $15-25$ & 17 & $04(23 \%)$ \\
\hline $25-40$ & 16 & $07(43 \%)$ \\
\hline$>40$ & 12 & $08(66 \%)$ \\
\hline
\end{tabular}

Mean of maximum OI was 42.4 (23.8-60) in nonsurvivor group, compared to a mean of maximum OI of $19.4(14.6-24.23)$ in survivors $(p=0.0013)$.
Maximum OI was a significant predictor of mortality $(\mathrm{p}=0.0013)$ (Table 5).

Table 5: Outcome comparison between survivor and non-survivor groups

\begin{tabular}{|l|c|c|c|}
\hline & Survivor $(\mathbf{n}=\mathbf{5 9})$ & Non survivor(n=25) & p value \\
\hline Preterm & 11 & 07 & 0.388 \\
\hline Birth weight & $2.55(0.8-3.6)$ & $2.78(1.5-3.8)$ & 0.105 \\
\hline Sex (Male) & $44($ Male $)$ & $19($ Male $)$ & 1.00 \\
\hline Apgar $<$ at 5 minutes & 09 & 09 & 0.044 \\
\hline Admission $\mathrm{pH}$ & $7.29(7.25-7.32)$ & $7.19(7.11-7.26)$ & 0.0061 \\
\hline Admission $\mathrm{PaO}_{2}$ & $58.4(46.02-70.9)$ & $51.5(37.8-65.3)$ & 0.51 \\
\hline Left ventricle dysfunction & 02 & 07 & 0.0024 \\
\hline Surfactant & 37 & 11 & 0.263 \\
\hline Maximum oxygenation index & $19.4(19.6-24.23)$ & $42.4(23.8-60)$ & 0.0013 \\
\hline Total duration of ventilation & $7.1(5.9-8.2)$ & $5.08(3.3-6.8)$ & 0.011 \\
\hline Multiple inotropes & 19 & 18 & 0.0015 \\
\hline Sepsis & 09 & 05 & 0.74 \\
\hline Air leak & 08 & 05 & 0.51 \\
\hline Ventilator associated pneumonia & 07 & 02 & 0.71 \\
\hline Nosocomial sepsis & 08 & 03 & 1.00 \\
\hline Intracranial haemorrhage & 02 & 04 & 0.074 \\
\hline Hospitalisation duration & $14.6912 .6-16.6)$ & $5.96(3.9-7.9)$ & $<0.0001$ \\
\hline
\end{tabular}

Left ventricular dysfunction was present in 7 (28\%) babies, out of 25 death cases (Figure 1). All neonates with left ventricular dysfunction needed multiple inotropes. Requirement of multiple inotropes was a statistically significant predictor of mortality $(\mathrm{p}=0.0015)$ (Figure 2). 


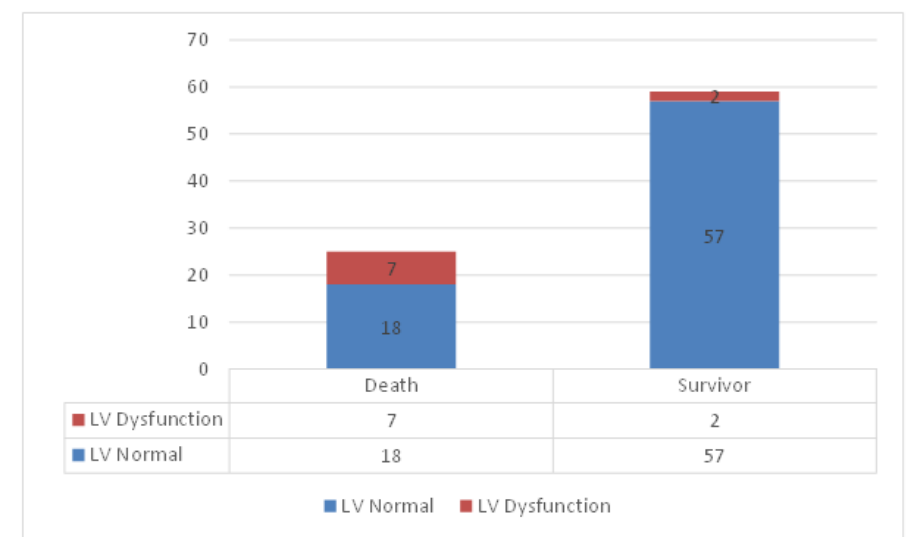

Figure 1: Outcome based on presence of left ventricular dysfunction

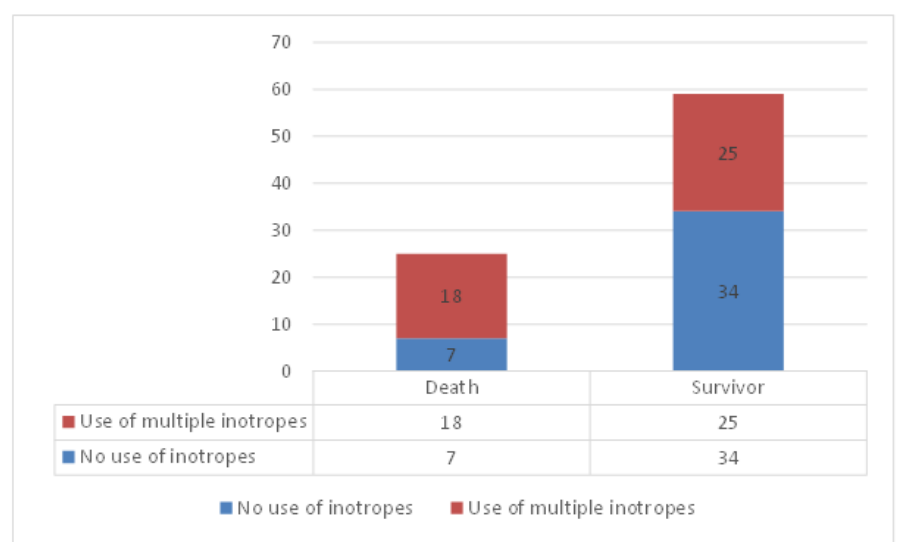

Figure 2: Outcome depending on use of multiple inotropes

Among 84 neonates, 71 neonates had sterile blood culture and 13 babies had culture positive sepsis. Among 59 survived babies, 9 babies had culture positive sepsis and out of 25 death cases, 5 babies had culture positive sepsis (Figure 3 ). The presence of culture positive sepsis at the time of admission did not have statistical significant effect $(p=0.74)$ on mortality.

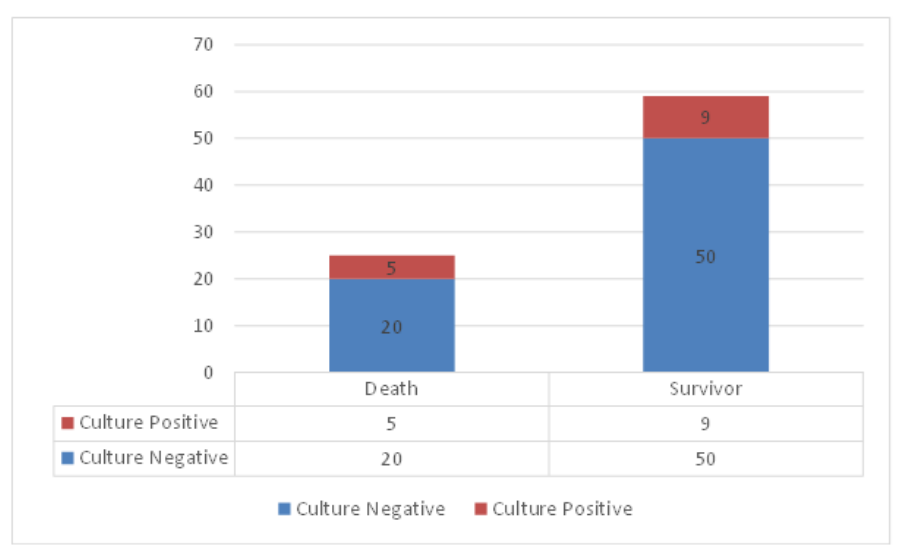

Figure 3: Outcome of babies with culture positive sepsis

Babies with ventilation associated pneumonia (VAP) had longer duration ventilation (11.4 days) in comparisons to neonates without VAP (6.5 days). Similarly neonates with VAP had longer duration of hospital stay (18.4 days) than babies having no VAP (11.8 days) which is shown in Figure 4. However presence of VAP $(p=0.71)$ had no statistical significant effect on mortality. 


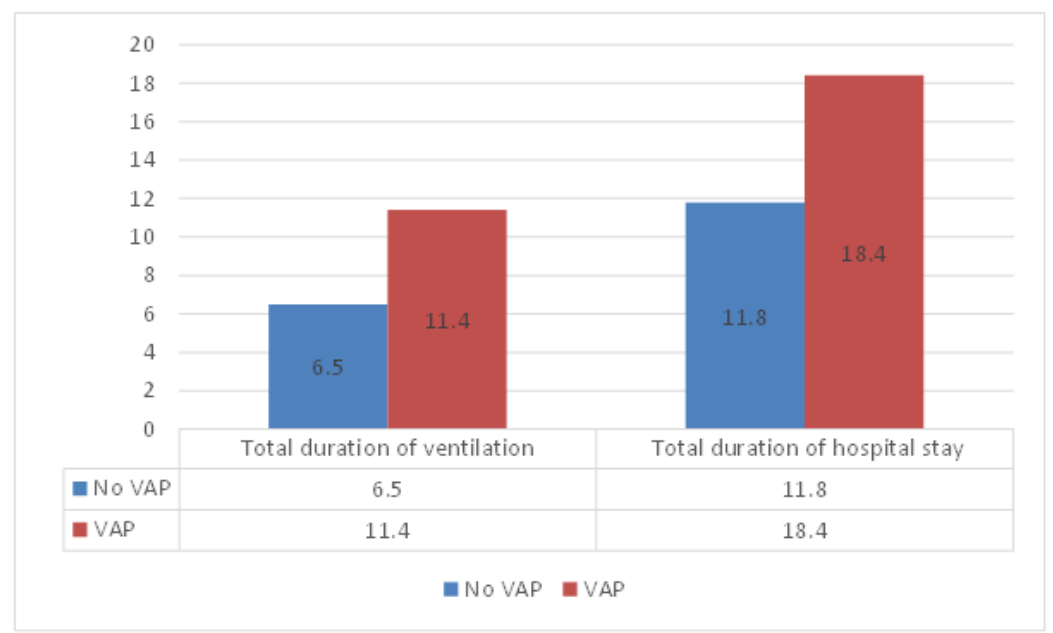

Figure 4: Outcome of babies with ventilation associated pneumonia

Babies with late onset sepsis had more prolonged duration of ventilation (10.2 days) than noninfective babies (6.5 days) and longer hospital stay (21.2days) than other babies (11.8 days). However nosocomial culture positive sepsis had no statistically significant effect $(\mathrm{p}=1.00)$ on mortality (Figure 5).

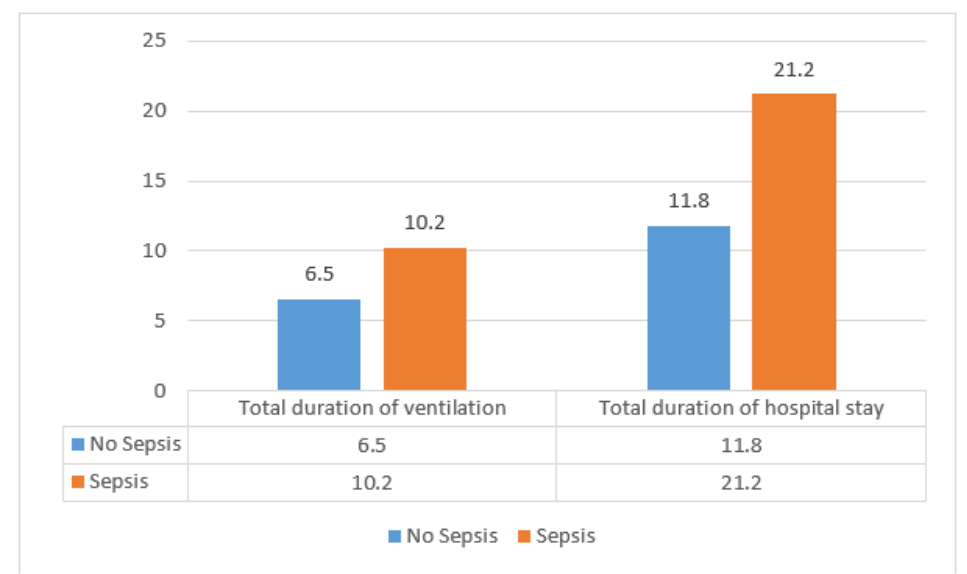

Figure 5: Outcome of babies with nosocomial sepsis

Considering the PPHN-related mortality, we did not observe a difference based on gestational age, gender or birth weight. Mean admission $\mathrm{pH}$ among survivors was $7.29(7.25-7.32)$ whereas it was 7.19 (7.11-7.26) among non-survivors which is statistically significant $(\mathrm{p}=0.006)$. Mean maximum oxygenation index OI among survivors was 19.4 (19.6-24.23) whereas the same among non survivors was $42.4(23.8-60)$ which is a significant predictor $(\mathrm{p}=0.0013)$ of mortality (Table 5).

In our study admission $\mathrm{pH}(\mathrm{p}=0.006)$, maximum OI $(\mathrm{p}=0.0013)$, Apgar score $<5$ at 5 minutes $(\mathrm{p}=0.044)$, presence of LV dysfunction $(\mathrm{p}=0.0024)$ and requirement of multiple inotropes $(\mathrm{p}=0.0015)$ were significant predictors of higher mortality (Table 5).
In our study surfactant (CUROSURF) was used in $48(57 \%)$ cases. In $92 \%$ of HMD and $72 \%$ of MAS cases, surfactants were used to improve oxygenation. We have observed that $59 \%$ cases of MAS with PPHN and $48 \%$ cases of HMD with PPHN required HFOV for management. $78 \%$ cases of CDH with PPHN required HFOV during clinical management. Sildenafil was used as pulmonary vasodilator in all cases. MgSO4 was used in eighteen cases by monitoring serum $\mathrm{Mg}$ level. Inhalational NO was not used during management as the facility was not available in our hospital.

\section{Discussion}

In our study the incidence of mortality was $30 \%$ which is lower than other study where it was $31 \%{ }^{11}$. Prior to the introduction of extracorporeal membrane oxygenation (ECMO) support, mortality 
rates were reported to be ranging from 12 to $50 \%{ }^{12}$. ECMO support has increased survival to about $85 \%$ in infants with severe persistent pulmonary hypertension of the newborn. In our study survival rates in neonates having MAS and HMD with PPHN were $77 \%$ and $72 \%$ respectively. $50 \%$ of neonates with $\mathrm{CDH}$ survived after PPHN management and post-surgery. In Walsh-Sukys et al survival rate was $94 \%$ in MAS, $91 \%$ in RDS or pneumonia, and $61 \%$ in $\mathrm{CDH}$ with $\mathrm{PPHN}^{2}$ whereas $57 \%$ of MAS ventilated neonates with PPHN were associated with higher mortality rate of $48 \%$ in the other study ${ }^{13}$.

In the present study relative risk of death was higher in neonates with $\mathrm{CDH}(\mathrm{RR}=1.94,95 \% \mathrm{CI} 1.007$ $3.54)$, followed by hypoplasia of lung $(\mathrm{RR}=1.77$, $95 \% \mathrm{CI} 0.73-4.2$ ) and this difference is also found to be statistically significant. Neonates having underdevelopment patho-physiology lung lesions like hypoplasia and $\mathrm{CDH}$ had higher relative risk of death $(\mathrm{RR}=2.1,95 \%$ CI 1.12-3.97, $\mathrm{P}=0.047)$ compared to neonates with maldevelopment lung conditions like MAS, RDS, Primary PPHN, pneumonia. Roofthooft MTR, et $a l^{11}$ in a logistic regression analysis observed that $\mathrm{OI}(\mathrm{p}=0.02)$ and type of pathophysiological mechanism $(\mathrm{p}<0.001)$ were independent predicting risk factors for PPHNrelated mortality.

In our study, admission $\mathrm{pH}(\mathrm{p}=0.006)$, Apgar score $<5$ at $5 \mathrm{~min}(\mathrm{p}=0.044)$, echocardiography finding of presence of LV dysfunction $(\mathrm{p}=0.0024)$ and requirement of multiple inotropes $(\mathrm{p}=0.0015)$, maximum OI $(\mathrm{p}=0.0013)$ were significant predictors of higher mortality (Table V). Davis et $a l^{12}$, multivariate discriminant analysis of risk factors of mortality among PPHN showed that lowest $\mathrm{pH}$, critical $\mathrm{PaCO}_{2}$, highest inspiratory pressure (PI), maximum ventilator rate, and 5minute Apgar score were significantly different between the 35 survivors $(66 \%)$ and the 18 nonsurvivors $(34 \%)$.

Aggarwal S et $a l^{14}$ found, LV dysfunction with PPHN as echocardiography marker of mortality in CDH group. In Skinner JR et al ${ }^{15}$, they have found that low LV output and stroke volume with normal LV function were Doppler echocardiography parameters to predict death. In our study $\mathrm{CDH}$ was the leading cause of mortality $(50 \%)$ and more number of asphyxiated neonates in the mortality group explained the significance of LV dysfunction as predictor of mortality. We have not measured left ventricular output or stroke index in our study and LV dysfunction was determined by low ejection fraction and contractility.

OI is a sensitive indicator of the severity of hypoxia and OI greater than 25 correlates with $50 \%$ risk
$(80 \%$ if $\mathrm{OI}>40)$ of mortality and/or need for $\mathrm{ECMO}^{16}$. Mean of maximum OI was 42.4 (23.8-60) in non-survivor group, whereas mean of maximum OI was 19.4 (14.6-24.23) in survivors $(p=0.0013)$. In our study babies having OI more than 25 had 53\% risk of mortality and risk was further increased to $65 \%$, if OI $>40$. UK ECMO neonatal trial found that the mortality rate in neonates who received ECMO therapy was $32 \%$, while the mortality rate in neonates having severe respiratory failure (OI $>40)$ who received conventional therapy was almost $60 \%{ }^{17}$. In our study, mortality was $80 \%$ if OI was more than 40 which can be due to delayed referral of neonates with respiratory failure from outside. PPHN was associated with B-haemolytic group B streptococci and group A streptococcal infection in some cases whereas listeriosis was found in some cases with fatal $\mathrm{PPHN}^{18}$. In our study population, 13 (15\%) neonates had positive blood cultures at the time of admission. Klebsiella spp. (most common), followed by Acinetobacter spp. and Candida spp. were isolated in blood culture. Rode ME, et $a l^{19}$ presented two cases who initially presented to the neonatal intensive care unit with PPHN but later had culture-proven secondary infection associated with significant recurrent PPHN. Thatrimontrichai $\mathrm{A}$, et $a l^{20}$ noted gram-negative organisms in $94 \%$ of tracheal aspirates of neonates with VAP. In our study 9 babies had ventilator associated pneumonia and 11 neonates had late onset sepsis. Babies with nosocomial sepsis and VAP required longer duration of ventilation and hospital stay. However presence of nosocomial culture positive sepsis $(p=0.74)$ or VAP ( $p=1.00)$ had statistically no significant effect on mortality.

The limitation of our study was that it was conducted in a level 3 centre and $88 \%$ babies were referral cases. As the study included hypoxic neonates, delayed referral and usage of high pressures to ventilate in absence of NO therapy might have affected the outcome. Non availability of ECMO and nitric oxide secondary to resource limitation may have skewed the result. It is conducted in a level three unit in a resource limited country where NO and ECMO facility was not available, but still mortality of our study is comparable to other studies conducted in developed countries.

\section{Conclusions}

PPHN is a serious and often fatal condition, associated with a high mortality (30\%). Nosocomial sepsis and ventilator associated pneumonia increased the total duration of ventilation, hospital stay with no effect on mortality. There was no significant difference in incidence of moderatesevere disease, requirement of HFOV, mortality among preterm and term babies. Relative risk of death was higher in $\mathrm{CDH}$ followed by lung hypoplasia. Underdevelopment patho-physiology 
lung lesions (hypoplasia and $\mathrm{CDH}$ ) had statistical significant risk of death compared to maldevelopment (MAS, RDS, primary PPHN, pneumonia). Admission $\mathrm{pH}$, Apgar score $<5$ at 5 min, presence of LV dysfunction and requirement of multiple inotropes, maximum OI were significant predictors of higher mortality.

\section{References}

1. Aslam HM, Saleem S, Afzal R, Iqbal U, Saleem SM, Shaikh MWA, et al. "Risk factors of birth asphyxia." Italian Journal of Pediatrics 2014; 40: 94. https://doi.org/10.1186/s13052-014-00942

PMid: 25526846 PMCid: PMC4300075

2. Walsh-Sukys MC, Tyson JE, Wright LL, Bauer CR, Korones SB, Stevenson DK, et al. Persistent pulmonary hypertension of the newborn in the era before nitric oxide: Practice variation and outcomes. Pediatrics 2000; 105(1 Pt I):14-20.

https://doi.org/10.1542/peds.105.1.14

PMid: 10617698

3. Steurer MA, Jelliffe-Pawlowski LL, Baer RJ, Partridge JC, Rogers EE, Keller RL. Persistent pulmonary hypertension of the newborn in late preterm and term infants in California. Pediatrics 2017; 139(1): e20161165.

https://doi.org/10.1542/peds.2016-1165

PMid: 27940508

4. Distefano G, Sciacca P. Molecular physiopathogenetic mechanisms and development of new potential therapeutic strategies in persistent pulmonary hypertension of the newborn. Italian Journal of Pediatrics 2015; 41: 6. https://doi.org/10.1186/s13052-015-01110

PMid: 25887340 PMCid: PMC4328557

5. Jain A, McNamara PJ. Persistent pulmonary hypertension of the newborn: Advances in diagnosis and treatment. Seminars in Fetal and Neonatal Medicine 2015; 20(4):262-71.

https://doi.org/10.1016/j.siny.2015.03.001

PMid: 25843770

6. Chetan G, Rathisharmila R, Narayanan P, Vishnu Bhat B. Persistent pulmonary hypertension of the newborn. Biomedicine 2007; 27(4):136-42.
7. Puthiyachirakkal M, Mhanna MJ. Pathophysiology, management, and outcome of persistent pulmonary hypertension of the newborn: A clinical review. Frontiers in Pediatrics 2013; 1: 23. https://doi.org/10.3389/fped.2013.00023 PMid: 24400269 PMCid: PMC3864198

8. Bendapudi P, Rao GG, Greenough A. Diagnosis and management of persistent pulmonary hypertension of the newborn. Paediatric Respiratory Reviews 2015; 16(3):157-61.

https://doi.org/10.1016/j.prrv.2015.02.001

PMid: 25765845

9. Porta NFM, Steinhorn RH. Pulmonary vasodilator therapy in the NICU: Inhaled nitric oxide, sildenafil, and other pulmonary vasodilating agents. Clinics in Perinatology 2012; 39(1):149-64. https://doi.org/10.1016/j.clp.2011.12.006 PMid: 22341543 PMCid: PMC3562500

10. Bendapudi P, Barr S. Diagnosis and management of pulmonary hypertension of the newborn. Paediatrics and Child Health 2014; 24(1):12-6.

https://doi.org/10.1016/j.paed.2013.05.021

11. Roofthooft MTR, Elema A, Bergman KA, Berger RMF. Patient characteristics in persistent pulmonary hypertension of the newborn. Pulmonary Medicine 2011; 2011: 858154.

https://doi.org/10.1155/2011/858154

PMid: 21660250 PMCid: PMC3109632

12. Davis JM, Spitzer AR, Cox C, Fox WW. Predicting survival in infants with persistent pulmonary hypertension of the newborn. Pediatric Pulmonology 1988; 5(1):6-9. https://doi.org/10.1002/ppul.1950050103 PMid: 3140200

13. Velaphi S, Van Kwawegen A. Meconium aspiration syndrome requiring assisted ventilation: Perspective in a setting with limited resources. Journal of Perinatology 2008; 28(2008):S36-42.

https://doi.org/10.1038/jp.2008.155

PMid: 19057609

14. Aggarwal S, Stockmann P, Klein MD, Natarajan G. Echocardiographic measures of ventricular function and pulmonary artery size: Prognostic markers of 
congenital diaphragmatic hernia. Journal of Perinatology 2011; 31(8):561-6.

https://doi.org/10.1038/jp.2011.3

PMid: 21311494

15. Skinner JR, Hunter S, Hey EN. Haemodynamic features at presentation in persistent pulmonary hypertension of the newborn and outcome. Archives of Disease in Childhood 1996; 74(1):26-32.

https://doi.org/10.1136/fn.74.1.F26

PMid: 8653431 PMCid: PMC2528330

16. England TN. With hypoxic respiratory failure. Medicine (Baltimore) 1997; 336:597-604.

https://doi.org/10.1056/NEJM1997022733 60901

PMid: 9036320

17. Bennett CC, Johnson A, Field DJ, Elbourne D. UK collaborative randomised trial of neonatal extracorporeal membrane oxygenation: Follow-up to age 4 years. Lancet 2001; 357(9262):1094-6. https://doi.org/10.1016/S0140-

6736(00)04310-5

18. Girardin E, Berner M, Grau GE, Dayer JM, Roux-Lombard P, Suter S. Tumour necrosis factor in neonatal listeriosis: a case report. European Journal of Pediatrics 1989; 148(7):644-5.

https://doi.org/10.1007/BF00441521

PMid: 2744036

19. Rode ME, Morgan MA, Ruchelli E. Clinical Perinatal / Neonatal Case Presentation Candida chorioamnionitis after serial therapeutic amniocenteses: A possible association. Journal of Perinatology 2000; 5: 335-7. https://doi.org/10.1038/sj.jp.7200381

PMid: 10920796

20. Thatrimontrichai A, Rujeerapaiboon N, Janjindamai W, Dissaneevate S, Maneenil G, Kritsaneepaiboon S, et al. Outcomes and risk factors of ventilator-associated pneumonia in neonates. World Journal of Pediatrics 2017; 13(4):328-34. https://doi.org/10.1007/s12519-017-00100

PMid: 28120236 